\title{
UMA REFLEXÃO DO PROCESSO DE APROPRIAÇÃO DOS RESULTADOS EM QUATRO ESCOLAS DA REDE ESTADUAL DE ENSINO DO AMAZONAS
}

\author{
Andréa Machado - SEDUC/AM ${ }^{1}$ \\ Rosângela Veiga Júlio Ferreira ${ }^{2}$ \\ Daniel Eveling da Silva ${ }^{3}$
}

\begin{abstract}
Resumo
O texto em questão, baseado em uma pesquisa de mestrado profissional em Gestão e Políticas Públicas, discute a gestão de resultados em quatro escolas da rede estadual de ensino do município de Borba, no estado do Amazonas. O plano de fundo da discussão é o de que as avaliações em larga escala tornaram-se um importante instrumento para aferir a qualidade do ensino ofertado nas escolas, principalmente para auxiliar o direcionamento de políticas públicas de melhoria da qualidade educacional, o que implica uma reflexão em torno de processos de apropriação dessa política que gera outras políticas públicas de educação. Neste texto analisamos como a gestão conduz o processo de apropriação dos resultados das avaliações em larga escala entre a comunidade escolar e as estratégias utilizadas para promover a reflexão sobre o uso dos resultados e os desafios de melhoria da qualidade do ensino. Sob o aporte teórico da análise de conteúdo foram definidos gestores e professores de Língua Portuguesa e Matemática como sujeitos de pesquisa, entrevistados na perspectiva teórica da entrevista semiestruturada. Com base nos dados da pesquisa, constata-se que os gestores se apropriam das informações geradas pelos indicadores, todavia, não é consensual entre os entrevistados que a política pública contribui para a promoção da melhoria da qualidade da educação pública. Verifica-se também que não há uma compreensão de especificidades que constituem o processo de avaliar em larga escala, mas identificam-se mudanças na organização escolar e no trabalho pedagógico docente, sob a justificativa de que é preciso melhorar os indicadores.
\end{abstract}

Palavras-chave: Avaliação externa. Gestão escolar. Apropriação de resultados.

\section{A REFLECTION OF THE APPROPRIATION PROCESS OF THE RESULTS IN FOUR SCHOOLS OF THE STATE OF EDUCATION OF THE AMAZONES}

\footnotetext{
Abstract

${ }^{1}$ Mestra em Gestão e Avaliação da Educação Pública pela Universidade Federal de Juiz de Fora (UFJF), Graduada em Pedagogia pela Universidade Federal do Amazonas (UFAM), Atualmente exerce a função de técnica pedagógica da Gerencia de Formação Acompanhamento e Avaliação de Programas e Projetos (GEAQ) do Centro de Formação Padre José de Anchieta (CEPAN) da Secretaria Estadual de Educação e Qualidade do Ensino (SEDUC).

${ }^{2}$ Doutora em Educação pela Universidade Federal de Juiz de Fora (UFJF).

3 Possui doutor (2016) em História pela Universidade Federal de Juiz de Fora.
} 
The text in question, based on a master's degree research in Management and Public Policies, discusses the management of results in four schools of the state education network of the municipality of Borba, in the state of Amazonas. The background of the discussion is that large-scale evaluations have become an important instrument for measuring the quality of teaching offered in schools, mainly to help guide public policies to improve educational quality, which implies a reflection around processes of appropriation of this policy that generates other public policies of education. In this paper we analyze how management conducts the process of appropriating the results of large-scale evaluations between the school community and the strategies used to promote reflection on the use of results and the challenges of improving the quality of teaching. Under the theoretical contribution of content analysis, managers and teachers of Portuguese and Mathematics were defined as subjects of research, interviewed in the theoretical perspective of a semistructured interview. Based on the research data, it is clear that managers take ownership of the information generated by the indicators. However, it is not consensual among the interviewees that public policy contributes to improve the quality of public education. It is also verified that there is no understanding of the specificities that constitute the process of largescale evaluation, but changes in school organization and teaching pedagogical work are identified, on the grounds that indicators need improvement.

Key words: External evaluation; School management; Appropriation of results.

\section{INTRODUÇÃO}

As reformas educacionais têm provocado mudanças significativas na dinâmica da escola, na qual a qualidade do ensino se constitui em um tema amplamente debatido nas diferentes instâncias governamentais, tendendo a provocar o direcionamento de políticas públicas nas quais os parâmetros legais qualitativos sejam atendidos. Ciente de que, assim como quaisquer outras políticas públicas, as avaliações em larga escala apresentam limites e possibilidades de concretização, identificamos uma relação direta entre o que se preconizam documentos legais para a promoção de ações de equidade na educação e o que se diagnosticam nessas avaliações (BROOKE; CUNHA, 2010).

As avaliações externas fornecem indícios sobre o desempenho dos alunos, podendo detectar, inclusive, possíveis pontos de melhorias do processo escolar (MACHADO, 2016). Tais avaliações, ao fornecerem informações da realidade escolar, podem auxiliar no processo de estabelecimento de ações estratégicas em prol da qualidade educacional. Destacamos serem as avaliações externas aferidoras de princípios de desempenho e de construção de habilidades, ou seja, buscam compreender a construção de determinadas características básicas de desenvolvimento, definindo, para tanto, padrões que permitem a comparabilidade e 
a verificação da apropriação de habilidades. Já as avaliações internas são responsáveis por acompanharem o processo de desenvolvimento cognitivo de um determinado conceito de forma não padronizada.

Vale ressaltar que temos a compreensão de que a avaliação em larga escala não é uma panaceia que irá resolver todos os problemas educacionais, no entanto, temos a clareza de que é um importante mecanismo capaz de mensurar a qualidade do ensino oferecido nas escolas, o que poderá contribuir de forma significativa para a efetivação da aprendizagem de todos os estudantes. Essa definição corrobora a posição expressa por Pimenta (2012, p. 52) de que "as avaliações podem ser úteis para o aprimoramento do trabalho escolar, desde que entendidas como consultivas da prática pedagógica". As avaliações focalizam o desempenho cognitivo dos estudantes. Isso implica um processo de reflexão e de direcionamento de ações pedagógicas que atendam à necessidade de aprendizagem dos estudantes.

Para Bonamino e Souza (2012) as avaliações em larga escala constituem-se em três gerações distintas e diferentes. A primeira corresponderia à implementação do Sistema de Avaliação da Educação Básica Brasileiro. Já a segunda e a terceira seriam estruturadas por meio dos sistemas estaduais e dos sentidos de responsabilização atribuídos às avaliações externas. No caso apresentado nesse texto, focamos centralmente nas características das duas últimas gerações apresentadas pelas autoras. Um ponto a ser analisado diz respeito ao Índice de Desenvolvimento da Educação do Estado do Amazonas - IDEAM -, estruturado como uma política de responsabilização na qual se busca envolver diferentes sujeitos educacionais nas questões pertinentes à rede estadual de ensino, como melhoria da educação, participação social e responsabilização frente aos resultados apresentados. Noutras palavras, os resultados das avaliações externas são apropriados também pela Secretaria de Educação ao divulgar os resultados e controlar a premiação das escolas, definida pela média de proficiência adquirida pelos alunos.

Temos ciência do peso adquirido e de que a divulgação e a compreensão de resultados podem adquirir na melhoria da educação pública do estado, principalmente se considerarmos o quanto tem sido investido na formação continuada de gestores e de professores. Todavia, entendemos ser importante problematizar outros efeitos do processo de ranqueamento das escolas, como, por exemplo, a intensificação de competições pautadas em treinamento condicionado de 
itens, o que pode ampliar a possibilidade de profissionais de educação obterem bonificações ${ }^{4}$.

Visto tais questões, elencadas acima, e frente ao aporte teórico destinado à compreensão do papel que a avaliação em larga escala veio adquirindo no cenário nacional ao longo da última década do século passado, questionamo-nos no texto aqui desenvolvido: Como a gestão das escolas investigadas vem se apropriando dos resultados da avaliação em larga escola? Essas apropriações geram efeitos na prática pedagógica dos profissionais da escola? E se sim, de que natureza são?

Trabalhamos com a hipótese de que o gestor exerce um papel fundamental na gestão do conhecimento dessa política pública e pode mobilizar estratégias gestoras cada vez mais sofisticadas de apropriação de resultados com a tomada de consciência de limites e possibilidades. Diante disso, poderá contribuir para o aprimoramento de intervenções pedagógicas em um currículo longitudinal, com progressões claramente definidas, que a médio e longo prazos trarão impactos substantivos nos indicadores nacional e estadual.

Frente a tais considerações este texto objetiva compreender como os contextos de apropriação e análise dos resultados da Prova Brasil na rede estadual de ensino de Borba-AM ocorrem ${ }^{5}$. Movidos pela concepção de que o processo de apropriação de resultados requer a compreensão de meandros de constituição da política pública da avaliação em larga escala, dominando conceitos que a formam e

\footnotetext{
${ }^{4}$ Estados como o Rio de Janeiro, até 2015, promoviam políticas de bonificação das escolas e de professores, caso as metas das avaliações externas fossem atingidas. A composição da média, no caso fluminense, deveria levar em conta o SAERJINHO, avaliação externa bimestral. No Estado do Amazonas, elementos como $14^{\circ}, 15^{\circ}$ e $16^{\circ}$ salário podem ser pagos às escolas de acordo com o Índice de Desenvolvimento da Educação do Estado do Amazonas. Não somos contrários ao reconhecimento docente e institucional das escolas com boas notas, entretanto, é urgente combater práticas institucionais que privilegiem tais elementos como sinônimos de qualidade e efetividade do processo educacional. Cf: MEDEIROS, Denise Barra. Os efeitos da política de bonificação do estado do Rio de Janeiro nas ações gestoras das escolas estaduais do município de Valença. Dissertação (Mestrado profissional em Gestão e Avaliação da Educação) - Centro de Políticas Públicas e Avaliação da Educação da Universidade Federal de Juiz de Fora, 2014. COSTA, Darlem Lúcia de Oliveira. Concepção dos Professores sobre a Política de Bonificação do Estado do Amazonas. Dissertação (Mestrado profissional em Gestão e Avaliação da Educação) - Centro de Políticas Públicas e Avaliação da Educação da Universidade Federal de Juiz de Fora, 2016.

${ }^{5} \mathrm{~A}$ análise aqui apresentada se apoia na pesquisa de mestrado que resultou na seguinte dissertação: "O gestor escolar e os desafios da apropriação dos resultados das avaliações em larga escala: impactos de intervenções pedagógicas em quatro escolas amazonenses". Nela, Andréa Cavalcante Machado ponderou como os resultados das avaliações externas eram utilizados pelos docentes. Pretendeu-se o fim de suscitar ações pedagógicas que primem pela melhoria do processo de ensino e aprendizagem das unidades de ensino, com os indícios fornecidos pelas avaliações externas. A pesquisa analisou de que forma os gestores conduziam o processo de apropriação dos resultados, quais desafios enfrentavam e quais estratégias utilizavam para promover reflexões sobre os resultados compreendidos pela comunidade escolar.
} 
sabendo operar com as informações que dela advêm, definimos para as entrevistas semiestruturas das profissionais da Coordenadoria Regional de Educação de Borba - AM, gestores e professores de Língua Portuguesa e Matemática do 5ำ Ano do Ensino Fundamental, no universo de quatro escolas. Após as entrevistas, optamos por usar a análise do conteúdo, que pautou as análises na compreensão dos elementos/termos: "apropriação"; "aprendizagem"; "resultados"; "simulados", "desempenho". A escolha por tais elementos permitiu "identificar o que est[ava] sendo dito a respeito d[o] tema" (VERGARA, 2005, p. 15) em tela, no caso, avaliação em larga escala.

Para discutir os aspectos anteriormente elencados, organizamos o texto em três partes articuladas, além da introdução e das considerações finais. A primeira é dedicada a considerações sobre as avaliações externas e suas contribuições para a melhoria da qualidade do ensino. A segunda contempla ação gestora em tempos de avaliação em larga escala. A terceira apresenta em linhas gerais a caracterização da rede estadual de ensino do Amazonas, seguida do contexto no qual as escolas estão inseridas. A subsequente tece considerações sobre os dados coletados dialogando com autores que tratam da temática estudada.

\section{A AVALIAÇÃO EXTERNA E A QUALIDADE DA EDUCAÇÃO BRASILEIRA}

As discussões sobre a qualidade da educação têm se intensificado nas últimas décadas, suscitando o uso dos testes padronizados como um dos pontos fundamentais para aferir o nível de ensino ofertado nas escolas. Nesse sentido, as avaliações em larga escala ganham proeminência, uma vez que permitem aferir o conhecimento dos estudantes no final do ciclo de ensino, bem como fornecem subsídios para o direcionamento de políticas públicas capazes de contribuir com a melhoria educacional, além de proporcionar indícios da realidade escolar, podendo ser apropriadas para reflexão dos processos pedagógicos na busca pela melhoria do ensino nas escolas públicas brasileiras.

No Brasil, as avaliações externas adquiriram centralidade nas políticas públicas da educação a partir da década de 1990, quando foi criado o Sistema de Avaliação da Educação Básica (SAEB). Essa avaliação externa se caracteriza como uma das primeiras iniciativas brasileiras que tinha como finalidade conhecer problemas e identificar deficiências do sistema educacional. Buscava-se à época um 
diagnóstico da situação educacional do país, primeira etapa, consoante a Sousa e Bonamino (2012), das avaliações em larga escala no país ${ }^{6}$.

No ano de 2005, o SAEB incorporou duas avaliações complementares em sua estruturação: a Avaliação Nacional da Educação Básica (ANEB) e a Avaliação Nacional do Rendimento Escolar (ANRESC), conhecida como Prova Brasil, ambas avaliando estudantes de Língua Portuguesa e Matemática. A primeira, de caráter amostral, é realizada nas redes públicas e particulares visando subsidiar a formulação de políticas educacionais que primem pela melhoria da qualidade da educação. Já a segunda censitária objetiva mensurar a qualidade do ensino oferecido nas escolas, fornecendo informações sobre padrões de desempenho, considerando parâmetros estatísticos de discriminação, dificuldade e acerto ao acaso, assim como a comparabilidade dos estudantes nos anos considerados estratégicos no processo de escolarização.

Outra mudança a ser considerada no contexto da política educacional de avaliação em larga escala foi a criação do Índice de Desenvolvimento da Educação Básica (IDEB), no ano de 2007, que visava avaliar a qualidade da educação básica. Em linhas gerais, esse índice pretende mensurar o trabalho desenvolvido pelas unidades de ensino, possibilitando o monitoramento do desempenho dos alunos e facilitando a comparabilidade dos resultados. Para Horta Neto (2010), a importância da comparabilidade do desempenho dos estudantes é que é possível mapear a realidade e, consequentemente, atuar sobre ela, a fim de superar as dificuldades apresentadas.

Devemos destacar, também, o ano de 2013, quando foi criada mais uma avaliação em larga escala: a Avaliação Nacional da Alfabetização (ANA), prevista no Pacto Nacional da Alfabetização na Idade Certa (PNAIC), com objetivo de estimar os níveis de alfabetização e letramento em Língua Portuguesa e Matemática. Horta Neto (2010, p. 92), esclarece que "um dos propósitos da avaliação é que ela possa contribuir para a melhoria da qualidade da educação", uma vez que se definiram os oito anos de idade uma etapa fundamental para as políticas de formação de professores nesse ano e nos anteriores.

\footnotetext{
${ }^{6}$ O SAEB, desde sua criação, passou por várias modificações, como: inserção da Teoria da Resposta ao Item, que permite identificarmos as margens estatísticas do acerto e erro das provas, definição de matrizes de referências, entre outros.
} 
Frente a tais momentos das políticas avaliativas externas, consideremos tais preocupações governamentais um instrumento de gestão que, quando compreendido, tende a contribuir para a orientação de outras políticas públicas educacionais, podendo auxiliar na melhoria da qualidade da educação. Assim, entendemos ser importante uma compreensão ampliada do que está direta ou indiretamente implicado com essa política.

Nesse sentido de busca pela compreensão dos significados e sentidos a que os profissionais da educação atribuem, cabe destacar que, como apontam Sousa e Bonamino (2012), resistências acontecem durante o processo, pois tende a existir uma valorização excessiva dos resultados. Essa característica pode influenciar na interpretação de que é necessário dominar o gênero "teste em larga escala" por meio de treinamentos em torno dos domínios, competências e descritores que concorrem para a identificação de fases do desenvolvimento cognitivo dos estudantes de um dado ano/série, considerando o recorte do currículo determinado pela definição da matriz de referência. "Ensinar para o teste" tem sido uma escolha, considerada estratégica, por escolas públicas que buscam a melhoraria do desempenho em testes padronizados.

As escolas e os sistemas educacionais que centram seus esforços e atenções somente no "ensinar para o teste" podem comprometer o cumprimento do currículo e o desenvolvimento da aprendizagem discente. Dessa forma, é importante registrar, conforme os aportes de Casassus (2009, 73), que "a medição aprisiona o sistema numa dinâmica perniciosa na procura da qualidade, que tem como consequência o efeito contrário ao esperado". Tal fato se justifica pela importância dada aos resultados das avaliações, pois, ao publicar a média das escolas, também as coloca em situação de julgamento, ou seja, põe-se na berlinda a qualidade do ensino, que se transforma em média mensurada por meio dos testes padronizados.

Ao tratarmos da qualidade da educação, os documentos legais coadunam para que os entes federados se organizem de maneira articulada a fim de proporcionar à população estudantil um ensino pautado nos pilares da equidade e qualidade. Nesse sentido, deve-se destacar a confluência com o proposto no inciso III, do artigo 214, da CF (BRASIL, 1988) e a meta 7 do Plano Nacional de Educação (BRASIL, 2014). Influenciada pelas determinações da Carta Magna, a política pública da avaliação em larga escala busca fomentar a qualidade da educação em todas as etapas da Educação Básica e melhorar o fluxo escolar, influenciando na 
média nacional do IDEB. Cabe mencionar que é nesse contexto que as avaliações em larga escala ganham destaque, uma vez que permitem aferir o conhecimento dos estudantes no final do ciclo de ensino, cujos dados diagnosticados contribuem de forma efetiva na definição de políticas públicas estaduais e municipais em seus respectivos planos de ação. Ao partir dessas percepções, as diferentes redes estaduais do país criaram seus próprios sistemas de avaliação em larga escala ${ }^{7}$. Os diferentes entes federados objetivaram com essa política pública mensurar a qualidade do ensino e proporcionar uma ampla visão do cenário educacional, buscando diagnosticar problemas de diferentes naturezas, por meio dos questionários contextuais (problemas advindos de questões relativas à aprendizagem, infraestrutura escolar, formação dos profissionais, entre outras), tal qual a política diagnóstica nacional.

Embora nossa opção tenha sido por trazer críticas no que tange à apropriação da política de avaliação em larga escala na perspectiva do campo da psicologia behaviorista estímulo-resposta, há que se considerar que tais avaliações são importantes mecanismos para aferir o nível de conhecimento dos estudantes na passagem entre segmentos de ensino ou ao final do processo de escolarização. Destarte, acreditamos que essas avaliações poderão contribuir de forma significativa para a melhoria educacional. Machado (2012, p. 71) destaca que "avaliar é um processo que pode ter como integrante o levantamento sistemático de informações dos alunos em testes padronizados, mas não se esgota nele". Assim, acreditamos que, se esses resultados forem tratados de forma adequada, poderão contribuir de forma substantiva para a melhoria do processo educacional.

Nessa perspectiva, em 2008, o Estado do Amazonas criou o seu próprio sistema de avaliação: o Sistema de Avaliação do Desempenho Educacional do Amazonas (SADEAM), com objetivo de promover um diagnóstico da rede pública de ensino; aferir o desempenho dos alunos; monitorar a qualidade da educação ao longo do tempo; e subsidiar a elaboração de políticas educacionais voltadas para a melhoria da qualidade do ensino.

Embora a questão da qualidade esteja associada às avaliações em larga escala, Machado (2012) demarca o debate apontando a necessidade de que os

\footnotetext{
${ }^{7}$ A título de explicação, podemos citar o Sistema Mineiro de Avaliação (SIMAVE), Sistema Permanente de Avaliação da Educação Básica do Ceará (SPAECE), o Sistema de Avaliação Educacional de Rondônia (SAERO).
} 
resultados dessas avaliações sejam incorporados ao planejamento da escola, como fonte de informação da realidade escolar, suscitando a reflexão e o direcionamento de ações pedagógicas para a efetivação da aprendizagem dos alunos. A autora afirma que

Refletir sobe como as escolas vêm, ou não, analisando e utilizando os resultados das suas práticas consolidadas na Prova Brasil e no Ideb e estimular a apropriação competente do uso dos resultados por parte dos profissionais da escola são condições para assegurar a melhoria da qualidade das escolas (MACHADO, 2012, p. 73).

Nessa perspectiva, a utilização dos resultados de processos avaliativos, seja a nível nacional seja a estadual, torna-se crucial para análise do trabalho desenvolvido nas escolas, uma vez que fornecem informações precisas, que muitas vezes não estão explícitas para o coletivo. A termos como ponto de partida essas questões, um profissional da escola surge como provável "mobilizador" das discussões e preocupações sobre o uso das avaliações externas: o gestor. Ele, ao ter conhecimento dos significados da avaliação, poderá contribuir, junto a sua equipe gestora e aos professores, para o processo de apropriação dos dados oriundos das avaliações externas.

\section{A GESTÃO ESCOLAR NO CONTEXTO DAS AVALIAÇÕES EM LARGA ESCALA}

A gestão da informação, a de pessoas, a de currículo, a de resultados de avaliação, entre outros aspectos que compõem a escola, colocam-se como de fundamental importância para a apropriação de políticas públicas. Assim, o desempenho dos alunos tornou-se, nas duas últimas décadas, o centro das atenções, apresentando-se como diagnóstico do trabalho da escola, ao mesmo tempo em que legitimou o uso das avaliações externas para medir a eficácia da escola e dos professores no cumprimento dessa tarefa. Essa percepção torna-se preocupante ao provocar possíveis reducionismos do processo educacional, como o não trabalho com o currículo em uma perspectiva ampliada, que considere aspectos cognitivos, sem sombra de dúvidas, mas também atitudinais e procedimentais, além de uma aproximação com atividades artístico-literárias que contribuem para a imaginação e para a criatividade.

É oportuno frisar que toda avaliação pressupõe uma ação com base nos resultados obtidos e, segundo Sousa e Oliveira (2010, p. 801), "ao realizar determinado processo avaliativo, espera-se, explicitamente, verificar quão distante 
se está da situação desejável e, a partir daí, definir elementos para modificar a situação em direção ao padrão desejado". Portanto, é natural que os resultados suscitem uma nova dinâmica no interior da escola, desde que essas mudanças tenham o objetivo de melhorias no processo de ensino e aprendizagem e levante-se uma atitude reflexiva sobre o aferido pela avaliação.

Nesse contexto, o gestor pode se tornar o principal responsável pelo espaço educacional, pois é ele quem coordena, lidera, articula, motiva e mobiliza a comunidade escolar para o alcance das metas e dos objetivos da escola. É importante salientar que as avaliações externas são importantes instrumentos de gestão, pois proporcionam uma gama de informações que, se apropriada de forma adequada, poderá contribuir para a melhoria do ensino. No entanto, o gestor, ao criar condições para que essas informações sejam compreendidas pelos diferentes sujeitos educacionais, como pais, alunos, professores e funcionários da escola, poderão contribuir para uma apropriação que rompa os treinamentos, também conhecidos como "aulões” e/ou simulados. De acordo com Lück (2009),

a gestão escolar constitui uma dimensão e um enfoque de em educação, que objetiva promover a organização, a mobilização e a articulação de todas as condições materiais e humanas necessárias para garantir o avanço dos processos socioeducacionais dos estabelecimentos de ensino, orientados para a promoção efetiva da aprendizagem dos alunos (p. 24).

Vemos, a partir da autora acima, uma centralidade na gestão escolar como mecanismo proporcionador das condições necessárias para o bom funcionamento da escola, além de promover um espaço de diálogo e de troca de informações, em que as ações futuras sejam sistematicamente planejadas e executadas com vistas à melhoria educacional. O gestor, e, em nossa percepção, a equipe diretiva, ao gerenciarem e articularem o trabalho dos professores e dos funcionários para objetivos e metas estabelecidos, pode garantir a realização de um trabalho pedagógico voltado para a formação integral do aluno.

Vale lembrar que a gestão escolar também passou por um processo de mudança para atender as demandas da sociedade contemporânea, acompanhando o modelo de gestão da sociedade na qual está inserida. No atual cenário educacional, as considerações sobre o trabalho de gestão apontam para a necessidade de um trabalho mais dinâmico, que suscite a participação e o envolvimento da comunidade escolar, pois quando os sujeitos educacionais 
participam das tomadas de decisão, também se sentem responsáveis por seus resultados (LÜCK, 2009).

Ponderando sobre a importância do papel da gestão escolar e o potencial das avaliações externas para a melhoria da qualidade do ensino, foi desenvolvida a pesquisa que focou sua análise na ação gestora e no processo de apropriação dos resultados em quatro escolas da rede estadual de ensino do município de Borba no Estado do Amazonas, considerando também o ponto de vista de professores de Língua Portuguesa e Matemática. Nessa direção é que procuramos compreender de que forma os resultados chegam à escola e se esses resultados são analisados pela comunidade escolar, a fim de reverberar em ações pedagógicas que priorizem a aprendizagem dos alunos.

Portanto, essa forma de gestão requer a construção de uma escola que aposta na autonomia de docentes e discentes, aberta ao diálogo e à participação da comunidade, mantendo o foco na melhoria da aprendizagem dos alunos - tarefa que demanda novos conhecimentos, atitudes e valores (NEUBAUER; SILVEIRA, 2009). Com essas concepções gestoras trazemos ao leitor deste texto, na sequência, uma breve descrição do contexto da pesquisa e considerações sobre o caso de gestão.

\section{A REDE PÚBLICA DO AMAZONAS: EVIDÊNCIAS DO SISTEMA EDUCACIONAL EM BORBA-AM}

A rede pública estadual do Amazonas, na época da realização da pesquisa na qual se originou este artigo, era composta por 696 escolas, sendo 230 na capital e 466 no interior. No ano de 2013, ano base da pesquisa, atendeu a um público de 433.874 alunos na Educação Básica. Dentre eles, 93.587 são dos anos iniciais do Ensino Fundamental, 168.970 dos anos finais do Ensino Fundamental e 171.279 alunos do Ensino Médio (BRASIL, 2015a).

Para atender as demandas educacionais, a Secretaria de Estado de Educação do Amazonas conta com duas secretarias adjuntas vinculadas a ela: a da Capital, formada por sete Coordenadorias Distritais, que acompanham o trabalho das escolas situadas na sede; e a do Interior, composta pelas Coordenadorias Regionais. Ambas têm como atribuição coordenar e controlar as atividades desenvolvidas nas escolas, promovendo a execução das políticas e diretrizes voltadas à educação. 
Com relação à política de resultados, a SEDUC-AM desenvolve alguns programas federais como o Pacto Nacional pela Alfabetização na Idade Certa (PNAIC), que visa garantir que todos os estudantes matriculados na rede pública de ensino, estejam efetivamente alfabetizados até aos oito anos de idade, ao concluir o $3^{\circ}$ ano do Ensino Fundamental. Havia ainda a primeira versão do Programa Mais Educação, o qual buscava, em tese, desenvolver atividades lúdicas, esportivas e reforço escolar nas disciplinas de Língua Portuguesa e Matemática. Outros programas estaduais podem ser exemplificados com o Reforço Escolar "Criando Oportunidades" e Programa Ciência na Escola (PCE), que visavam trabalhar as dificuldades dos alunos oferecendo aulas de reforço no contra turno, bem como garantir a transformação do pensar e fazer científico do cidadão.

No que tange à apropriação dos resultados das avaliações externas, a Secretaria Estadual de Educação do Estado do Amazonas promove formação para gestores e pedagogos das escolas estaduais, contudo, para as escolas localizadas no interior do estado, essas formações acontecem via centro de mídia, ou seja, são transmitidas por vídeo conferência. Nesse sentido, cabe ao gestor repassar as informações à comunidade escolar, visto que, as escolas não têm pedagogo, nem professor de apoio pedagógico. A falta desses profissionais compromete o desempenho da gestão pedagógica, visto que, na maioria das vezes, o gestor empreende muito do seu tempo em trabalhos administrativos e burocráticos, deixando o pedagógico sob a responsabilidade dos professores.

Outra estratégia utilizada pela Secretaria para melhorar os resultados educacionais das escolas da rede estadual de ensino do Amazonas foi a política de bonificação, tática utilizada pelo Governo do Estado por meio da Secretaria de Educação, com premiações para as escolas e profissionais da educação pelo seu desempenho, visando incentivar as escolas na busca de melhores resultados. Com isso, aumenta a pressão dos governos para que as unidades de ensino obtenham média de crescimento contínuo.

As quatro escolas que compõem o aporte da pesquisa estão localizadas no município de Borba, interior do estado do Amazonas com cerca de $210 \mathrm{~km}$ de distância da Capital. As escolas aqui analisadas estão sob a jurisdição da Coordenadoria Regional de Educação e Qualidade do Ensino, composta por doze escolas, das quais sete estão localizadas na zona urbana e cinco na zona rural. Para análise escolhemos as instituições responsáveis por atender alunos dos anos 
iniciais do Ensino Fundamental, que receberam nomes fictícios de Escola A, Escola $B$, Escola C e Escola D. Os sujeitos de pesquisa aqui usados são identificados como Professor 1, Professor 2 e assim sequencialmente até o Professor 8. Já em relação aos gestores, identificamos como Gestor 1 e 2 . Justificamos essa forma de referência para mantermos o anonimato dos respondentes, devido a características éticas de pesquisa. Optamos por tais sujeitos educacionais por suas escolas atenderem estudantes dos anos iniciais do Ensino Fundamental e pertencerem a mesma coordenadoria. Presumimos, assim, que recebem as mesmas orientações da Secretaria estadual para os trabalhos com os resultados. Contudo, constata-se nas evidências do caso que as instituições apresentam médias distintas no Índice de Desenvolvimento da Educação Básica (IDEB) e no Índice de Desenvolvimento Educacional do Amazonas (IDEAM), conforme apresentado na tabela a seguir:

Tabela 1 - IDEB/ IDEAM - 5을 Ano do Ensino Fundamental

\begin{tabular}{lc|c|c|c|c|c}
\hline & ESCOLAS & IDEB & IDEAM & IDEB & IDEAM & IDEB \\
& 2009 & 2010 & 2011 & 2012 & 2013 \\
\hline Escola A & 4.0 & 4.1 & 4.1 & 4.2 & 4.9 \\
Escola B & 3.8 & 3.3 & 4.7 & 4.1 & 3.8 \\
Escola C & 4.9 & 4.6 & 5.0 & 4.7 & 5.0 \\
Escola D & 4.3 & 3.9 & 4.0 & 4.1 & 4.8 \\
\hline
\end{tabular}

Fonte: Tabela elaborada pela autora a partir de dados da SEDUC/AM (2015).

$\mathrm{Na}$ Tabela 1 temos a série histórica das médias das escolas, observa-se certa oscilação dos resultados comparando-as entre o IDEB e IDEAM. Entretanto, a Escola A vem demonstrando um crescimento gradativo, com percepção de melhorias no último IDEB observado. Esses dados despertaram o interesse em entendermos os motivos que levam as escolas a apresentarem índices tão distintos, mesmo recebendo, em tese, as mesmas orientações e acompanhamento pedagógico da equipe da coordenadoria.

Para discutir esses dados, organizamos a entrevista semiestruturada para os gestores com base questões em 26 questões, que versavam sobre o entendimento das avaliações externas e sobre as políticas desenvolvidas pela SEDUC-AM, a CRE e as escolas. Já as entrevistas para os professores constituíram-se com 29 perguntas com as mesmas temáticas. Buscamos, ao final da coleta de dados e da tabulação, contrastar as falas pela técnica da análise do conteúdo já mencionada, 
destacando palavras e expressões centrais como: aprendizagem; desempenho; apropriação; simulados; treinamentos; processos pedagógicos; currículo; matriz de referência; responsabilização, dentre outras. As entrevistas foram realizadas em visitas à escola e foram consentidas deixando o respondente à vontade para expressar suas opiniões e percepções sobre o processo, elucidando claramente a não existência de respostas certas ou erradas. A busca objetivava levantar como esses sujeitos se colocavam e compreendiam os processos da avaliação em larga escala, além dos procedimentos formativos (entendidos como discussão, divulgação, apropriação) e específicos das avaliações em larga escala. Para o desenvolvimento do artigo aqui apresentado, como veremos à frente, optamos por elencar apenas algumas das respostas.

Desse modo, procuramos conhecer a concepção do trabalho de gestão sob a ótica dos gestores e professores, objetivando investigar: (i) como ocorre a apropriação dos resultados das avaliações externas nas escolas pesquisadas; (ii) se as informações advindas dessas avaliações estão sendo utilizadas nas unidades de ensino com intuito de reverberar ações pedagógicas que primem pela melhoria educacional.

Esses elementos foram destacados, principalmente, pelo trabalho desenvolvido na Coordenadoria Regional de Educação, que, na estruturação dos seus trabalhos, desenvolve com sua equipe discussões referentes à apropriação dos resultados, sendo desenvolvidas reuniões com gestores e professores das escolas, priorizando aquelas que apresentaram baixo desempenho nas avaliações externas. Essa reunião tem o propósito de auxiliar os profissionais da escola a refletirem sobre os resultados, analisando os fatores que supostamente interferiram nos índices, bem como traçar ações estratégicas capazes de amenizar os déficits de desempenho detectados, levando em conta os pontos destacados para as possíveis intervenções. Com base nessa percepção, partimos para o campo para verificar o conhecimento dos diferentes sujeitos sobre a compreensão do modelo de avaliação externa. Identificamos que esse modelo de avaliação ainda é pouco compreendido pelos profissionais das escolas de Borba, embora reconheçam sua importância para a melhoria do processo educacional, o que pode ser constatado na leitura do excerto ${ }^{8}$ :

\footnotetext{
${ }^{8}$ Nossa opção é por apresentar os excertos das entrevistas realizadas com os profissionais das quatro escolas em itálico para diferenciar das citações recuadas.
} 
Essas avaliações externas, eu vejo como uma ferramenta positiva pra educação, pois através dessas avaliações o professor recebe cobranças e, com isso, ele tem que trabalhar uma série de habilidades que acaba sendo significativo para a formação do aluno (PROFESSOR 4, Escola B) ${ }^{9}$.

Essas avaliações têm tido de uma importância muito grande para os professores, porque ela nos dá um panorama de informações e até de comparação e equiparação das nossas crianças com outras escolas, e o diagnóstico que ela faz nos possibilita aprofundar mais o estudo dentro da sala de aula (PROFESSOR 5, Escola C) ${ }^{10}$.

Identificamos que os professores afirmam ter conhecimento da importância das avaliações para a melhoria do processo pedagógico da escola. Ao mesmo tempo, destacam a perspectiva de direcionamentos a serem seguidos dentro da sala de aula. Sabemos ser importantes os dados provenientes das avaliações externas, como formas de determinadas caracterizações da escola, mas simultaneamente não abarcam toda a complexidade dos processos de aprendizagem, acompanhados no dia a dia da sala de aula Assim, as falas dos Professores 4 e 5 colocam em cena a pressão sofrida por eles e pela escola para a melhoria dos indicadores educacionais. Não obstante a isso há uma aproximação dos dados das avaliações externas com outras realidades, podendo criar uma "competitividade" entre escolas e "crianças", colocando em cena outro dos possíveis efeitos enviesados da não compreensão dos dados provenientes das avaliações de larga escala. Ressaltamos os riscos que essas cobranças podem causar às escolas, induzindo "diretores e professores em preparar seus alunos para os testes, levando ao estreitamento do currículo" (SOUSA; BONAMINO, 2012, p. 386).

Nessa mesma direção Heloísa Lück (2009, p. 55) esclarece que "por melhores que sejam os processos de gestão escolar, pouco valor terão, caso não produzam resultados efetivos de melhoria da aprendizagem dos alunos". Já Lima (2013, p. 27) argumenta que "a avaliação é um meio de detectar dificuldades e reorientar o ensino, entende-se sua relevância como estratégia para a gestão escolar, para auxiliar na aprendizagem dos alunos". Cabe questionar pelas respostas: como podemos contornar os problemas para a compreensão dos processos avaliativos? Nessa mesma seara foi constatado em falas dos entrevistados, ao serem perguntados sobre as medidas pedagógicas tomadas na escola para melhorar o desempenho dos alunos nas avaliações externas, o

\footnotetext{
${ }^{9}$ PROFESSOR 4. Entrevista realiza em 20 de maio de 2016. Borba, 2016. (25:31 min).

${ }^{10}$ PROFESSOR 5. Entrevista realiza em 13 de maio de 2016. Borba, 2016. (46:46min).
} 
surgimento da percepção de que o foco da escola está na melhoria dos resultados. Isso pode ser percebido conforme pontuado nos trechos abaixo:

Os assuntos do plano bimestral são trabalhados através dos descritores, nos moldes da Prova Brasil. A escola faz simulado a cada bimestre. Agora na sala de aula a gente trabalha sempre com essas questões, exercitando (PROFESSOR 2, Escola A) ${ }^{11}$.

A escola faz simulado a cada bimestre, é cobrado assunto do bimestre abordando os descritores, nos moldes da Prova Brasil (PROFESSOR 3, Escola B) ${ }^{12}$. Também é feito simulado mensal, são trabalhados os assuntos do bimestre de acordo com os descritores (PROFESSOR 4, Escola B).

As avaliações internas da escola, como elas acontecem bimestralmente, nós estamos priorizando o conhecimento que é dado à criança no bimestre, mas todos os simulados trabalham em cima dos descritores que são cobrados nessa avaliação externa (PROFESSOR 5, Escola C).

A gente pauta 0 trabalho nos conteúdos que são cobrados nas avaliações externas e tenta dinamizar o trabalho, tornando significativo para os alunos. São realizados alguns projetos, simulado mensal, nesse simulado a gente tenta mesclar colocar o conteúdo do bimestre, mas contextualizando com os descritores também, o que vai cair na prova (PROFESSOR 8 , Escola D) ${ }^{13}$.

Ao nos debruçarmos sobre o grupo de excertos citados chama a atenção o quanto a preocupação com os resultados das avaliações em larga escala está presente no cotidiano dessas escolas. Falas como "os simulados trabalham em cima dos descritores que são cobrados nessa avaliação externa"; "de acordo com os descritores"; "colocando o conteúdo do bimestre, mas contextualizando com os descritores", permite-nos constatar o quanto a pressão por melhores resultados da avaliação em larga escala está colocada no cotidiano dessas escolas e impactam nas atividades escolares sob a justificativa de que um resultado negativo pode prejudicar a escola. Ao adotarem tal procedimento, o processo ensino-aprendizagem fica comprometido, tendendo a provocar um reducionismo das intervenções metodológicas. Ao mesmo tempo, outros professores, ao serem perguntados sobre os princípios centrais da escola, apontaram o seguinte:

Eu penso que a principal responsabilidade do professor em primeiro lugar é com o ensino e aprendizagem do aluno, e como segunda forma de opinião seria a formação dele dentro da sociedade, tentar de uma forma direta e indireta encaminhá-lo pra ser um cidadão

\footnotetext{
${ }^{11}$ PROFESSOR 2. Entrevista realiza em 17 de maio de 2016. Borba, 2016. (35:01min).

12 PROFESSOR 3. Entrevista realiza em 19 de maio de 2016. Borba, 2016. (31:54min).

${ }^{13}$ PROFESSOR 8. Entrevista realiza em 19 de maio de 2016. Borba, 2016. (20:07min).
} 
correto dentro da sociedade, procurando obedecer aos seus direitos e deveres (PROFESSOR 1, Escola A) ${ }^{14}$.

O professor tem que ter responsabilidade com a educação, responsabilidade com 0 aprendizado do aluno (PROFESSOR 3, Escola B).

O compromisso, "né", o comprometimento mesmo com nosso trabalho, sempre focado naquilo que temos que fazer, a educação não é fácil, focamos tanto na aprendizagem quanto na formação do aluno (PROFESSOR 6, Escola C) ${ }^{15}$.

As duas principais responsabilidades que eu penso ser as maiores é a orientação da aprendizagem dos educandos e a questão de ensinar valores éticos e morais também para os alunos (PROFESSOR 8, Escola D).

Ao compararmos as passagens sobre as avaliações externas e os excertos recortados notamos pontos de vista diferentes. As primeiras destacaram um processo de utilização de simulados e descritores das avaliações contrastando com os objetivos educacionais mais amplos, como os pontuados pelos outros professores nos quais apontam a preocupação dos docentes, devendo ser não só com os conteúdos que deverão ser trabalhados naquela etapa de escolaridade em que os estudantes se encontram, mas também com sua formação, ao considerarem uma das responsabilidades da escola. Tal aspecto coaduna com Lück (2009, p. 21), quando aclara que "os alunos são as pessoas para quem a escola existe e para quem deve voltar as suas atenções, de modo que todos tenham o máximo sucesso nos estudos que realizam para sua formação pessoal e social".

Quanto à apropriação dos resultados das avaliações em larga escala, a equipe da coordenadoria reúne com gestores e professores em cada uma das quatro escolas para fazer análise de seus resultados. A partir daí, elaboram um plano de intervenção a ser trabalhado no decorrer do ano escolar, com intuito de intervir na dificuldade apresentada pelos alunos e, assim, promover melhoria na aprendizagem. Todavia, convém destacar a dificuldade que gestores e professores têm em interpretar os dados produzidos pelas avaliações externas, o que tem dificultado a realização de uma análise pedagógica dos resultados. Por esse motivo, as escolas focavam suas análises apenas na média de proficiência dos alunos. Tal fato direcionava estratégias em busca da melhoria dos índices educacionais.

Nessa perspectiva, algumas estratégias eram praticadas constantemente na escola, a fim de proporcionar melhoria da proficiência dos estudantes. A prática que parece ser mais forte é que as escolas trabalham a matriz curricular conferindo

\footnotetext{
${ }^{14}$ PROFESSOR 1. Entrevista realiza em 11 de maio de 2016. Borba, 2016. (44:27min).

${ }^{15}$ PROFESSOR 6. Entrevista realiza em 13 de maio de 2016. Borba, 2016. (23:90min).
} 
ênfase aos conteúdos contemplados na matriz de referência. Além do mais, as atividades realizadas na sala de aula são baseadas nos descritores da matriz de referência nos moldes da Prova Brasil.

O reforço escolar e o simulado são estratégias utilizadas pelas quatro escolas para melhorar o desempenho dos alunos.

A escola trabalha com reforço pra que o aluno possa melhorar [...]
Tem o simulado, que é feito mensalmente para obter o resultado com
êxito. O simulado é feito para diagnosticar a aprendizagem e treinar
para o teste, porque, ao fazer o simulado, nós estamos fazendo
dentro do horário, ou seja, tantos minutos para responder as
questões e mais tantos minutos para que ele preencha nos moldes
da Prova Brasil, com horário cronometrado (GESTORA 2, Escola
B) ${ }^{16}$.
A escola faz simulado a cada bimestre. É cobrado assunto do
bimestre abordando os descritores, nos moldes da Prova Brasil
(PROFESSOR 3 , Escola B).
O simulado acontece mensalmente. Trabalhamos não só os
conteúdos, mas os descritores que eles estão com mais dificuldades.
Na realidade, o simulado serve para trabalhar a aprendizagem e a
preparação para as provas, porque se ele conhece a forma dos
simulados, ele não vai se assustar na prova (PROFESSOR 7, Escola
D) ${ }^{17}$.

Apesar de ser uma boa tática para detectar as dificuldades apresentadas pelos alunos, fornecendo subsídios aos professores sobre a escolha da metodologia adequada para sanar as dificuldades dos alunos. Acreditamos, no entanto, que, ao simular questões com base nos descritores, corre-se o risco de treinar apenas para os testes, o que não produz melhoria na aprendizagem dos alunos.

Assim, destacamos a necessidade de gestores e professores em compreenderem o sentido das avaliações externas como mecanismos para diagnosticar o desempenho dos alunos e não como definidoras e estruturadoras do currículo escola e da rede. Ao nos depararmos com essas falas e expressões como: simulado, descritores, comparação e equiparação, em contraste com aprendizagem, formação, aprendizado. Colocou em cena a necessidade de entendermos o processo que vem sendo desenvolvido na escola e promovermos uma conscientização de como esses processos apresentam suas características específicas e, para além, como podemos compreendê-los em sua junção. Disso proveio a necessidade de pensarmos formações continuadas e sequenciais para os professores, gestores e demais profissionais da educação compreenderem as

\footnotetext{
${ }^{16}$ GESTORA 2. Entrevista realiza em 16 de maio de 2016. Borba, 2016. (39:42min).

${ }_{17}^{17}$ PROFESSOR 7. Entrevista realiza em 18 de maio de 2016. Borba, 2016. (44:12min).
} 
interseções dos processos e as avaliações em larga escala. Dentro de sua especificidade, elas devem ser notadas como "pistas e indícios" para ajudar o processo de desenvolvimento pedagógico da escola e não como a finalidade da educação que, como sabemos, deve ser a aprendizagem e a formação autônoma dos alunos.

\section{CONSIDERAÇÕES FINAIS}

As avaliações externas fomentam o estabelecimento de metas e a implantação de ações pedagógicas e administrativas no âmbito escolar. Além de direcionar soluções para os problemas detectados, contribuem para a projeção de políticas públicas voltadas para a melhoria do ensino oferecido nas escolas, primando por uma educação sustentada no pilar da qualidade e equidade.

$O$ texto identificou que, embora as avaliações externas façam parte da rotina da escola, gestores e professores apresentam dificuldades em interpretar os dados, o que conduz a uma análise superficial do desempenho dos alunos, conferindo ênfase à média de proficiência, o que contribui para o direcionamento de ações com foco nos resultados. Assim, fica evidente que as intervenções pedagógicas são sistematizadas com base na média de proficiência obtida pelos alunos nas avaliações externas, tornando-se um instrumento utilizado para a correção de rumos. Sabemos ainda ser o processo de interpretação dos dados advindos da avaliação externa como densos e necessários de articulação, dessa maneira nossa preocupação também destaca a necessidade de formação contínua do professor, percebendo-o como um elemento de construção do processo e, para isso, é fundamental a CRE estabelecer trabalhos consolidados para esses profissionais, pois a educação deve ser compartilhada por todos.

Embora a apropriação dos resultados ocorra de forma democrática com a participação de gestores e professores, os pais não participam desse processo. Eles são apenas informados das decisões tomadas pela escola para a melhoria do desempenho dos alunos nas avaliações em larga escala. Com base nessas constatações, podemos afirmar de que a apropriação dos resultados precisa ser vista como instrumento de reflexão pelos atores educacionais. Para tanto, é preciso que as informações advindas das avaliações externas sirvam como ponto de partida para a reflexão de um trabalho pedagógico, voltado para a melhoria da qualidade do ensino. 


\section{REFERÊNCIAS}

BRASIL. Constituição da República Federativa do Brasil, de 5 de outubro de 1988. Diário Oficial da União, Brasília, DF, 1988.

Educação.

Lei no 13.005, de 25 de junho de 2014. Institui o Plano Nacional de <http://www.planalto.gov.br/ccivil_03/_Ato20112014/2014/Lei/L13005.htm>. Acesso em: 15 ago. 2015.

. Instituto Nacional de Estudos e Pesquisas Educacionais Anísio Teixeira. Censo escolar 2011. Disponível em: <http://portal.inep.gov.br/basica-censo-escolarmatricula>. Acesso: 07 set. 2015a.

CASASSUS, Juan. Uma nota crítica sobre a avaliação estandartizada: a perda da qualidade e a segmentação social. Sísifo. Revista de Ciência da Educação, p. 71 79, 2009.

COSTA, Darlem Lúcia de Oliveira. Concepção dos Professores sobre a Política de Bonificação do Estado do Amazonas. Dissertação (Mestrado profissional em Gestão e Avaliação da Educação) - Centro de Políticas Públicas e Avaliação da Educação da Universidade Federal de Juiz de Fora, 2016.

GESTORA 2. Entrevista realizada em 16 de maio de 2016. Borba, 2016. (39:42min).

HORTA NETO, João Luiz. Avaliação externa de escolas e sistemas: questões presentes no debate sobre o tema. Revista Brasileira de Estudos Pedagógicos. Brasília, v. 91, n. 227, p. 84-104, jan./abr. 2010. Disponível em:

LIMA, Magali Bernardes Vargas de. A organização do trabalho de uma equipe gestora e o desempenho escolar dos alunos. 2013. Dissertação (Mestrado em Educação Escolar) - Programa de Pós-Graduação em Educação Escolar, Universidade Estadual Paulista, São Paulo, 2013.

LÜCK, Heloísa. As Dimensões da Gestão Escolar e suas competências. Curitiba: Positivo, 2009.

MACHADO, Cristiane. Avaliação Externa e Gestão Escolar: reflexões sobre o uso dos resultados. Revista @mbienteeducação, São Paulo, v. 5, n. 1, p. 70-82, jan./jun. 2012.

MACHADO, A. S. do R. C. O gestor escolar e os desafios da apropriação dos resultados das avaliações em larga escala: impactos de intervenções pedagógicas em quatro escolas amazonenses. 2016. 161f. Dissertação (Mestrado em Gestão e Avaliação da Educação Pública) - Universidade Federal de Juiz de Fora, Faculdade de Educação, Centro de Políticas Públicas e Avaliação da Educação, Programa de Pós Graduação em Gestão e Avaliação da Educação Pública, Juiz de Fora, 2016.

MEDEIROS, Denise Barra. Os efeitos da política de bonificação do estado do Rio de Janeiro nas ações gestoras das escolas estaduais do município de 
Valença. Dissertação (Mestrado profissional em Gestão e Avaliação da Educação) Centro de Políticas Públicas e Avaliação da Educação da Universidade Federal de Juiz de Fora, 2014.

NEUBAUER, R.; SILVEIRA, G.T. Gestão dos sistemas escolares- Quais caminhos seguir? In: SCHWARTZMAN, S.; COX, C. (editores). Políticas Educacionais e Coesão Social. Uma agenda Latino-Americana. Rio de Janeiro: Campus, 2009.

PIMENTA, Cláudia Oliveira. Avaliações externas e o trabalho de coordenadores pedagógicos: estudo em uma rede municipal paulista. 2012. 141 f. Dissertação (Mestrado em Educação) - Faculdade de Educação, Universidade de São Paulo, São Paulo, 2012.

PROFESSOR 1. Entrevista realiza em 11 de maio de 2016. Borba, 2016. (44:27min).

PROFESSOR 2. Entrevista realiza em 17 de maio de 2016. Borba, 2016. (35:01 min).

PROFESSOR 3. Entrevista realiza em 19 de maio de 2016. Borba, 2016. (31:54min).

PROFESSOR 4. Entrevista realiza em 20 de maio de 2016. Borba, 2016. (25:31 min).

PROFESSOR 5. Entrevista realiza em 13 de maio de 2016. Borba, 2016. (46:46min).

PROFESSOR 6. Entrevista realiza em 13 de maio de 2016. Borba, 2016. (23:90min).

PROFESSOR 7. Entrevista realiza em 18 de maio de 2016. Borba, 2016. (44:12min).

PROFESSOR 8. Entrevista realiza em 19 de maio de 2016. Borba, 2016. (20:07min).

SOUSA, Sandra Zákia; BONAMINO, Alícia. Três gerações de avaliação da educação básica no Brasil: interfaces com o currículo da/na escola. Educação e Pesquisa, São Paulo, v. 38, n. 2, p. 373-388, abr./jun. 2012.

. OLIVEIRA, Romualdo Portela de. Sistemas Estaduais de Avaliação: uso dos resultados, implicações e tendências. Cadernos de Pesquisa, São Paulo, v. 40, n. 141, p. 793-822, set./dez. 2010. 